\title{
Danielle Chadych et Charlotte Lacour-Veyranne, Paris au temps des Misérables de Victor Hugo
}

\section{Lise Sabourin}

\section{(2) OpenEdition}

1 Journals

\section{Édition électronique}

URL : http://journals.openedition.org/studifrancesi/6691

DOI : 10.4000/studifrancesi.6691

ISSN : 2427-5856

Éditeur

Rosenberg \& Sellier

\section{Édition imprimée}

Date de publication : 1 septembre 2010

Pagination : 389

ISSN : 0039-2944

\section{Référence électronique}

Lise Sabourin, « Danielle Chadych et Charlotte Lacour-Veyranne, Paris au temps des Misérables de Victor Hugo », Studi Francesi [En ligne], 161 (LIV | II) | 2010, mis en ligne le 30 novembre 2015, consulté le 08 janvier 2021. URL : http://journals.openedition.org/studifrancesi/6691 ; DOI : https://doi.org/ 10.4000/studifrancesi.6691

Ce document a été généré automatiquement le 8 janvier 2021.

\section{(c) $($ ) $\odot$}

Studi Francesi è distribuita con Licenza Creative Commons Attribuzione - Non commerciale - Non opere derivate 4.0 Internazionale. 


\title{
Danielle Chadych et Charlotte Lacour-Veyranne, Paris au temps des Misérables de Victor Hugo
}

\author{
Lise Sabourin
}

\section{RÉFÉRENCE}

DANIELLE CHADYCH et CHARLOTTE LACOUR VeYRANNE, Paris au temps des Misérables de Victor

Hugo, Musée Carnavalet-Histoire de Paris, 10 octobre 2008-1er février 2009, Paris Musées, 2008, pp. 152.

1 Ce catalogue d'une belle exposition tenue au Musée d'Histoire de Paris que constitue Carnavalet s'ouvre sur Une ode à Paris romantique sous la plume de Danielle CHADYCH (pp.11-38) avant la présentation des œuvres par les deux commissaires, classée autour des personnages de Fantine, Cosette, Marius, de l'idylle de la rue Plumet et de l'épopée de la rue Saint-Denis, de Jean Valjean enfin.

2 Les Misérables opèrent, on le sait, un judicieux mélange de réalité et de fiction, en une rêverie imaginative sur une ville abondamment fréquentée par leur auteur. Neuf lieux principaux, souvent théâtre d'épisodes de sa vie, ont inspiré ses descriptions: les Champs-Élysées, le $13^{\mathrm{e}}$ arrondissement du Boulevard de l'Hôpital et du champ de l'Alouette, les barrières érigées sur les boulevards extérieurs, le $5^{\mathrm{e}}$ arrondissement, le couvent fictif du Petit-Picpus, la rue Oudinot devenue Plumet dans le roman, le Luxembourg, les Halles et le Marais.

3 Un tableau placé à l'ouverture de l'exposition, Paris vu des hauteurs de Montmartre en 1822 de George Arnald (pp. 40-41), permet de prendre conscience du changement de taille de la capitale romantique par rapport à la métropole d'aujourd'hui: il était encore possible au piéton d'alors de rejoindre assez rapidement les champs.

4 Fantine donne à Hugo l'occasion de brosser le tableau du Paris de 1817 encore marqué des faits historiques récents qu'on s'efforce de gommer (tels les $\mathrm{N}$ aux frontons des 
monuments) mais aussi de se remémorer le bonheur de ses promenades de jeunesse aux Champs-Élysées.

Avec Cosette, le romancier s'élance dans les quartiers décrépits (la masure Gorbeau, les barrières d'Italie et Saint-Jacques) qui lui permettront d'élaborer son couvent de Picpus, dépaysé par précaution envers la censure du $12^{\mathrm{e}}$ arrondissement au quartier Saint-Antoine, par contamination des souvenirs de Léonie Biard et de Juliette Drouet sur les couvents des Bénédictines et des Dames de Sainte-Madeleine.

6 Marius, M. Gillenormand, Gavroche et les Thénardier permettent de nombreuses pérégrinations: des Grands-Boulevards au Marais, mais aussi de Saint-Sulpice au Luxembourg revivent l'idylle de jeunesse d'Adèle et Victor comme les reconstructions récentes du Paris historique. Le Paris de Louis-Philippe élève la colonne de la Bastille (voir l'eau-forte coloriée du Monument élevé à la mémoire des citoyens morts pour la Liberté. Paris en juillet 1831 et la lithographie sur la Colonne de Juillet, pp.106-107), tout en abandonnant l'éléphant maquette de 1813 envisagé pour fontaine par Napoléon, qui fournit à Gavroche un refuge bien propice à susciter la faculté visionnaire hugolienne (L'Éléphant de la Bastille, 1844, p. 108).

7 Jean Valjean secourant le héros de l'idylle de la rue Plumet tout autant que de l'épopée de la rue Saint-Denis permet de relater les émeutes de 1832, longuement étudiées sur archives du procès des accusés de la barricade Saint-Merri. Enfin après avoir transposé, à la date de sa première nuit d'amour avec Juliette, le mariage de Léopoldine en celui de Cosette et Marius à Saint-Paul-Saint-Louis, Hugo se voit, rue de l'Homme armé, dans le père accablé qu'il fait enterrer, comme le sien, au Père-Lachaise.

8 Parmi les tableaux, gravures, photographies, plans et objets présentés, signalons-en particulièrement quelques-uns pour la fixation d'imaginaire qu'ils ont permise aux visiteurs - et que les lecteurs pourront retrouver grâce à l'iconographie soignée du catalogue. Ainsi de ces barrières de Paris aujourd'hui quasi toutes disparues (et de toute façon plus perçues comme telles) que montrent l'aquatinte de 1830 sur La Barrière de Passy (p.53) et l'eau-forte de Cécile Marchand, Fragment près de la barrière de Fontainebleau vers 1810 (p. 55). Les vues de L'Hôpital de la Salpétrière (p. 57) ou du Dépôt des condamnés de Bicêtre en 1834 (p. 103), de la Barricade dans la rue Saint-Martin le 25 février 1848 (p.130) ou du Point où l'égout se déverse dans la Seine vers 1858 (p. 137) sont fort évocatrices des conditions matérielles de vie de la population, tandis que les font toucher du doigt et presque de l'oreille la menotte avec clef, dénommée Poucette avec chaîne (p. 95), et l'affiche de 1848, Argot et jargon: première et seule édition de l'argot et du jargon des filous qui n'est intelligible qu'entre eux (p. 113). 